\title{
Agomelatine for the Treatment of Generalized Anxiety Disorder: A Meta-Analysis
}

\author{
Sheng-Min Wang, Young Sup Woo, Nak-Young Kim, Hae-Ran Na, Hyun Kook Lim, Won-Myong Bahk \\ Department of Psychiatry, College of Medicine, The Catholic University of Korea, Seoul, Korea
}

\begin{abstract}
Objective: Despite multiple drugs available, a large proportion of patients with generalized anxiety disorder (GAD) do not show adequate response and remission. Thus, additional novel pharmacological agents are needed to increase treatment option for GAD. We aimed to investigate efficacy and safety of agomelatine in the treatment of GAD by conducting a meta-analysis.

Methods: An extensive search of multiple databases and clinical trial registries were conducted. Mean change in total scores on Hamilton Anxiety Rating Scale (HAM-A) from baseline to endpoint was our primary outcome measure. Secondary efficacy measures included response and remission rates, as defined by a $50 \%$ or greater reduction in HAM-A total scores and a score of 7 or less in HAM-A total scores at study endpoint respectively.

Results: Four published double blinded, randomized, placebo-controlled trials were included in this meta-analysis. Agomelatine more significantly (standardized mean difference $=-0.56, p=0.004$ ) improved HAM-A total scores than placebo. The odds ratios (ORs) of agomelatine over placebo for response and remission rates were $3.75(p<0.00001)$ and $2.74(p<0.00001)$, respectively. Agomelatine was generally well tolerated with insignificance in dropout rate, somnolence, headache, nasopharyngitis, and dizziness compared with placebo. However, agomelatine showed significantly higher incidence of liver function increment $(\mathrm{OR}=3.13, p=0.01)$ and nausea $(\mathrm{OR}=3.27, p=0.02)$. Conclusion: We showed that agomelatine may be another treatment option in patients with GAD. However, the results should be interpreted and translated into clinical practice with caution because the meta-analysis was based on limited numbers of clinical trials.
\end{abstract}

KEY WORDS: Agomelatine; Anxiety disorder; Clinical trial; Treatment; Meta-analysis.

\section{INTRODUCTION}

Generalized anxiety disorder (GAD) is a common and debilitating psychiatric disorder, with lifetime prevalence of $6 \%[1,2]$. The impairment of psychosocial functioning and magnitude of economic loss caused by GAD is comparable to that of major depressive disorder (MDD) [3-5]. Various drugs including benzodiazepines, selective serotonin reuptake inhibitors (SSRIs), serotonin noradrenaline reuptake inhibitors, tricyclic antidepressants, anticonvulsants, and atypical antipsychotics can be used to treat GAD

\footnotetext{
Received: March 5, 2020 / Revised: March 26, 2020

Accepted: March 27, 2020

Address for correspondence: Won-Myong Bahk

Department of Psychiatry, Yeouido St. Mary's Hospital, College of

Medicine, The Catholic University of Korea, 10 63-ro,

Yeongdeungpo-gu, Seoul 07345, Korea

E-mail:wmbahk@catholic.ac.kr

ORCID: https://orcid.org/0000-0002-0156-2510
}

[6-8]. However, only $50 \%$ of patients experience response with the first-line therapy [9], and less than $20 \%$ of patients achieve complete remission even after taking multiple drugs [10]. Therefore, additional novel pharmacological agents are needed to increase treatment option for patients with GAD.

Agomelatine is an antidepressant which was first approved in Europe in 2009 [11]. Its main mechanism of action includes agonist at melatonergic $\left(\mathrm{MT}_{1}\right.$ and $\left.\mathrm{MT}_{2}\right)$ receptors and antagonist at serotonergic $5-\mathrm{HT}_{2 \mathrm{C}}$ receptor. Animal studies including Vogel conflict procedure, elevated plus-maze procedure, conditioned footshock-induced ultrasonic vocalizations test, social defeat stress test, predator stress test, and the fear learning process suggested anxiolytic properties of agomelatine [12-14]. Studies further showed that agomelatine's anxiolytic property is mainly attributed from its $5-\mathrm{HT}_{2 \mathrm{C}}$ antagonism, but melatonin receptor may also be involved in decreasing anxiety

(ㄷ) This is an Open-Access article distributed under the terms of the Creative Commons Attribution Non-Commercial License (http://creativecommons.org/licenses/by-nc/4.0) which permits unrestricted non-commercial use, distribution, and reproduction in any medium, provided the original work is properly cited. 
[15]. In line with animal models, a study initially showed that agomelatine was effective in treating anxiety symptoms associated with depression [16]. Therefore, numerous randomized, double-blinded, placebo-controlled clinical trials (RCTs) demonstrated that agomelatine could be an effective and safe treatment option for patients with GAD $[17,18]$.

In terms of investigating potential efficacy and safety of a certain drug other than its approved conditions, metaanalysis is an important study method due to its methodological strengths. It can overcome limitation of small sample sizes, increase statistical power for group comparisons, enhance generalizability by including diverse trials conducted in various populations, investigate potential publication biases, and quantify and analyze inconsistencies in results across clinical studies [19-21]. Despite this importance, although multiple expert opinion reviews systemically described potential usage of agomelatine in patients with GAD $[9,22]$, no meta-analysis was conducted to statistically quantify benefits and drawbacks of agomelatine for patients with GAD. Thus, we performed a meta-analysis and investigated its efficacy and safety of agomelatine in the treatment of GAD.

\section{METHODS}

\section{Sources of Data}

We repeatedly searched PubMed, Embase, Pubmed, PsycINFO, Cumulative Index to Nursing and Allied Health Literature (CINAHL), Web of Science, and the Cochrane Central Register of Controlled Trials Library for published articles. In terms of clinical trials, ClinicalTrials.gov (www.clinicaltrials.gov) and International Standard Randomized Controlled Trial Number (ISRCTN) registry were explored. The article and clinical trial searches were conducted repeatedly from January 1 st to February 15th, 2020 using MeSH terms: "agomelatine," and "anxiety." Reference lists from identified articles and reviews were manually searched to find additional studies. Two authors (S.M.W. and N.K.K.) independently reviewed the abstracts identified from the literature search. Two other authors (H.R.N. and W.M.B.) re-evaluated potentially eligible papers to determine whether they truly met the selection criteria. The last two authors (H.K.L. and Y.S.W.) discussed and reached a consensus for disagreements.

\section{Inclusion Criteria for the Meta-analysis}

Primary inclusion criteria were all RCTs investigating the efficacy and safety of agomelatine for the treatment of GAD. To be included in our meta-analysis, studies were required to: 1 ) be in double-blinded and randomized in design; 2) have placebo as a comparator, regardless of having an active comparator, 3) have clearly described all inclusion and exclusion criteria; 4) compared the outcomes of the use of placebo and agomelatine in patients with GAD. No restrictions were utilized for severity of GAD, sex, treatment basis (i.e., inpatient or outpatient), pharmaceutical, dose range, or study location.

\section{Data Extraction, Quality Assessment, and Risk of Bias}

Data including author's names, year of publication, sample size, patients' characteristics (mean age, sex), duration of treatment, dosage, baseline findings, study location country, and study design were extracted using data-collection form. The quality of RCTs was also assessed based on Cochrane Review's recommendations [23]. The risk of bias in individual studies including sequence generation, allocation concealment, the blinding of participants and investigators, the blinding of outcome assessments, incomplete outcome data, selective outcome reporting, and other sources were independently assessed by the two authors (S.M.W. and W.M.B.).

\section{Study Outcomes}

The primary outcome measures were change from baseline to study endpoint in total score of Hamilton Anxiety Rating Scale (HAM-A). The secondary efficacy measures were rate of response (50\% or more decrement of HAM-A from baseline to endpoint) and remission (7 or less in total HAM-A score at endpoint). In terms of safety and tolerability, total number of adverse events (AEs) and numbers of dropouts due to AEs were included. Other common AEs including liver function test (LFT), nausea, somnolence, headache, nasopharyngitis, and dizziness were included in the meta-analysis.

\section{Statistical Analysis}

We used Review Manager Version 5.3 software (Cochrane Collaboration, Oxford, UK) to conduct statistical analysis. In terms of binary measures, odds ratio (OR) with 95\% confidence intervals $(\mathrm{Cl})$ using the Mantel-Haenszel method was used to present difference 
in change from baseline to endpoint between agomelatine and control groups. In addition, standardized mean difference (SMD) using the method developed by Hedges (Hedges g) with 95\% confidence intervals (95\% Cls) were utilized for continuous measures. The effect size (ES) can be evaluated based on Cohen's classification: small ES = SMD $<0.2$, medium ES $=$ SMD of 0.5 , and large ES = $\mathrm{SMD}>0.8$ [24]. In addition, $\mathrm{I}^{2}$ statistic was used to explore heterogeneity, which evaluates how much of the variance between studies can be attributed to the actual differences between the studies rather than to chance [25]. $\mathrm{I}^{2}$ of $75-100 \%$ indicates considerable hetero-

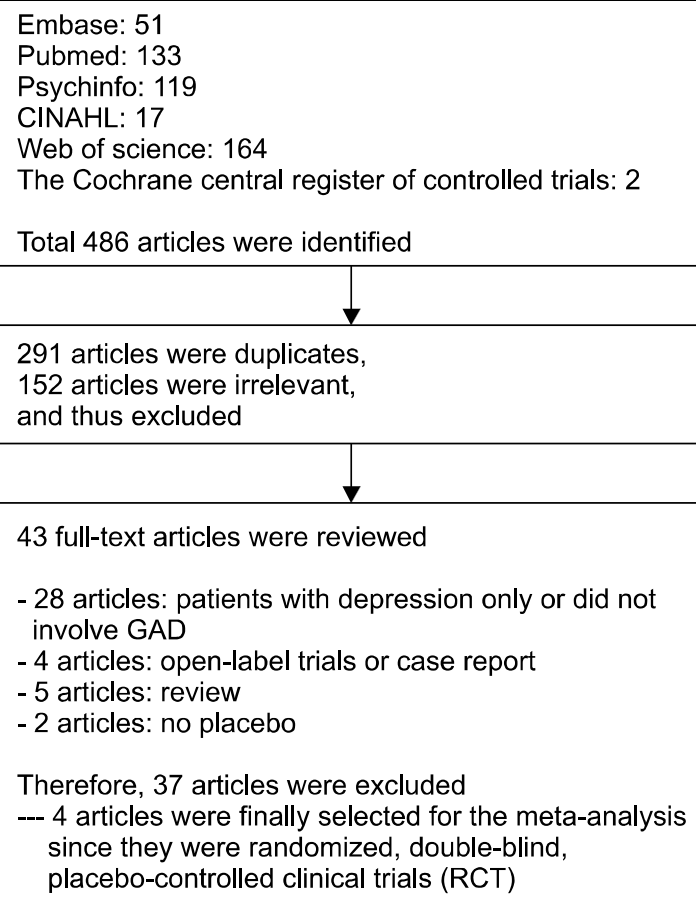

Fig. 1. Schematic presentation of studies selected in the present metaanalysis.

GAD, Generalized anxiety disorder; RCT, randomized, double-blinded, placebo-controlled clinical trial; ISRCTN, International Standard Randomized Controlled Trial Number. geneity, and the heterogeneity threshold was defined as $50 \%$ or more in $\mathrm{I}^{2}$ value and $p<0.1$.

We applied fixed-effects or random-effects models appropriately to perform analyses of primary and secondary measures. A random-effects model was used when $I^{2}$ indicated significant heterogeneity among study results $\left(\mathrm{I}^{2}>\right.$ $50 \%$ and $p<0.1)$. Studies showed that the random-effects model allows for sampling variability with and between studies, and smaller studies are weighted more whereas larger studies are weighted less. Thus, it is suggested to provide a more balanced analyses than the fixed effect model $[26,27]$.

\section{RESULTS}

\section{Study Characteristics}

Electronic searches yielded a total of 486 articles. After a preliminary review, 443 papers were excluded because they were either duplicates or irrelevant to our metaanalysis. The remaining 43 full-text articles were retrieved for a more detailed evaluation. After removing 28 articles not involving GAD, 4 open label or case studies, 5 reviews, and 2 clinical trials not having placebo, only 4 studies remained. Of the 21 records obtained from ClinicalTrials.gov, all were irrelevant to GAD. Among 21 clinical trials identified from ISRCTN, 17 clinical trials were irrelevant, and 4 trials involved RCT of GAD, but they were duplicates of the articles found in Pubmed. Thus, 4 articles were finally selected for the meta-analysis since they were randomized, double-blind, placebo-controlled clinical trials (Fig. 1).

Table 1 presents main characteristics of these 4 RCTs. All studies were multi-centered, multinational trials conducted outside of US. Three were short-term clinical trials with 12 weeks of study duration $[17,28,29]$. One trial involved a 26-week double-blinded, placebo-controlled trial in GAD patients who showed optimal remission with agomelatine [18]. A total of 1,024 participants were included, and number of patients included in placebo group and agomelatine groups were 442 and 582 respectively. Three studies used identical dose of agomelatine, 25 - 50 $\mathrm{mg} /$ day $[17,18,28]$. However, in one study, the agomelatine group was further randomized into agomelatine 10 $\mathrm{mg} /$ day or $25 \mathrm{mg} /$ day [29].

The risk of bias assessment showed that all studies included were good in quality in terms of their method- 
Table 1. Summary of RCTs of agomelatine for the treatment of generalized anxiety disorder

\begin{tabular}{|c|c|c|c|c|c|c|c|c|c|c|}
\hline \multirow{2}{*}{ Study } & \multirow{2}{*}{ Drugs $(\mathrm{mg} / \mathrm{d})$} & \multirow{2}{*}{$\begin{array}{l}\text { Patient } \\
\text { (n) }\end{array}$} & \multirow{2}{*}{$\begin{array}{l}\text { Mean } \\
\text { age (yr) }\end{array}$} & \multirow{2}{*}{$\begin{array}{l}\text { Duration } \\
\text { (wk) }\end{array}$} & \multirow{2}{*}{$\begin{array}{l}\text { Baseline } \\
\text { MADRS }\end{array}$} & \multicolumn{4}{|c|}{ Hamilton Anxiety Rating Scale } & \multirow{2}{*}{$\begin{array}{l}\text { Study } \\
\text { location }\end{array}$} \\
\hline & & & & & & Baseline & Mean change $^{\mathrm{a}}$ & Response $^{\mathrm{b}}$ & Remission $^{c}$ & \\
\hline \multirow{2}{*}{$\begin{array}{l}\text { Stein et al. } \\
2008 \text { [17] }\end{array}$} & PBO & 58 & 41.7 & 12 & $11.7 \pm 2.1$ & $28.6 \pm 3.8$ & $-13.2 \pm 9.5$ & 27 (46.6) & $13(22.4)$ & \multirow{2}{*}{ S. Africa, FN } \\
\hline & $\operatorname{AGO}(25-50)$ & 63 & 41.7 & & $11.6 \pm 2.9$ & $29.0 \pm 4.4$ & $-16.6 \pm 8.9$ & $42(66.7)$ & $26(41.3)$ & \\
\hline \multirow{2}{*}{$\begin{array}{l}\text { Stein et al. } \\
2012[18]\end{array}$} & $\mathrm{PBO}$ & 113 & 47.0 & 26 & NA & $6.0 \pm 2.6$ & $3.6 \pm 8.4$ & NA & NA & \multirow{2}{*}{$\begin{array}{c}\mathrm{CN}, \mathrm{DN}, \mathrm{ET}, \mathrm{FN}, \\
\mathrm{HG} \text {, and SW }\end{array}$} \\
\hline & $\operatorname{AGO}(25-50)$ & 112 & 45.9 & & NA & $5.9 \pm 2.7$ & $-1.6 \pm 7.7$ & NA & NA & \\
\hline \multirow{2}{*}{$\begin{array}{l}\text { Stein et al. } \\
2014[28]\end{array}$} & $\mathrm{PBO}$ & 131 & 43.0 & 12 & $12.3 \pm 2.4$ & $28.2 \pm 3.4$ & $-10.6 \pm 9.5$ & $48(36.6)$ & $26(19.9)$ & \multirow{2}{*}{$\begin{array}{c}\mathrm{FN}, \mathrm{RU}, \mathrm{PL}, \mathrm{CZ} \\
\mathrm{SL}, \mathrm{AG}, \mathrm{S} . \text { Korea }\end{array}$} \\
\hline & $\operatorname{AGO}(25-50)$ & 139 & 43.6 & & $12.0 \pm 2.4$ & $28.6 \pm 4.0$ & $-15.6 \pm 9.4$ & $89(64.0)$ & $51(36.7)$ & \\
\hline \multirow{4}{*}{$\begin{array}{l}\text { Stein et al. } \\
2017 \text { [29] }\end{array}$} & $\mathrm{PBO}$ & 140 & 44.1 & 12 & $11.5 \pm 2.6$ & $28.8 \pm 3.6$ & $-6.9 \pm 9.2$ & $32(22.9)$ & $18(12.9)$ & \multirow{4}{*}{$\begin{array}{l}\mathrm{FN}, \mathrm{RU}, \mathrm{PL}, \mathrm{SL} \text {, } \\
\text { Ukraine }\end{array}$} \\
\hline & AGO total & 268 & 43.9 & & $11.6 \pm 2.4$ & $28.8 \pm 3.7$ & $-15.91 \pm 8.19$ & $164(61.2)$ & $88(32.9)$ & \\
\hline & AGO (10) & 130 & 43.6 & & $11.8 \pm 2.4$ & $28.6 \pm 3.5$ & $-13.87 \pm 8.7$ & 67 (51.5) & $33(25.4)$ & \\
\hline & AGO (25) & 138 & 44.1 & & $11.4 \pm 2.4$ & $29.0 \pm 3.7$ & $-18.7 \pm 7.7$ & $97(70.3)$ & 55 (39.9) & \\
\hline
\end{tabular}

Values are presented as number (\%) or mean \pm standard deviation.

$\mathrm{RCT}$, randomized, double-blind, placebo-controlled trials; MADRS, Montgomery and Åsberg Depression Rating Scale; SD, standard deviation; PBO, Placebo; AGO, Agomelatine; NA, not applicable; S. Africa, South Africa; FN, Finland; CN, Canada; DN, Denmark; ET, Estonia, HG, Hungary; SW, Sweden; RU, Russia; PL, Poland; CZ, Czech Republic; SL, Slovakia; AG, Argentina; S. Korea, South Korea; HAM-A, Hamilton Anxiety Rating Scale.

${ }^{\mathrm{a}}$ Primary efficacy measure; ${ }^{\mathrm{b}}$ Response: $50 \%$ or more decrement of HAM-A from baseline to endpoint; ${ }^{\mathrm{c}}$ Remission: 7 or less in total HAM-A score at endpoint.

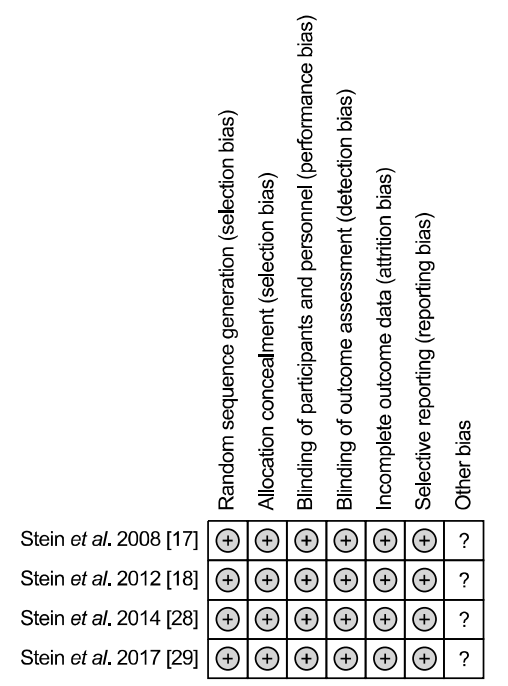

Fig. 2. Risk of bias in individual studies included in the metaanalysis.

ologies (Fig. 2). Publication bias could not be tested because there were too few studies for the various outcomes examined and all RCTs included were published studies.

\section{Efficacy}

\section{Primary endpoint: Mean change of HAM-A}

The result of the meta-analysis regarding the primary endpoints, mean change of HAM-A total score from baseline to study endpoint, are presented as forest plots (Fig. 3). Agomelatine (SMD, -0.56 [95\% Cl, -0.94 to -0.18$], p<$
0.0001) more significantly improved HAM-A total scores than placebo. Significant heterogeneity was reported $\left(\mathrm{I}^{2}=\right.$ $88 \%, p<0.0001$ ), so we used random effect model. A subgroup analysis was conducted to explain this heterogeneity. We hypothesized that heterogeneity occurred due to lack of overlap of confidence interval caused from one study having high SMD, Stein et al. 2017 [29] (SMD of -1.05). After excluding the study by Stein et al. 2017 [29], the heterogeneity became insignificant $\left(I^{2}=\right.$ $10 \%, p=0.33$ ) while significant superiority of agomelatine over placebo remained with lower effect size (SMD, $-0.39[95 \% \mathrm{Cl},-0.56$ to -0.22$])$. The study by Stein et al. 2014 [28] had a different design; GAD patients who showed significant remission from agomelatine were randomized to placebo to agomelatine. Thus, an additional subgroup analysis was conducted after excluding this study, which showed that the effect size of agomelatine became greater (SMD, $-0.66[95 \% \mathrm{Cl},-1.08$ to -0.24$]$ ), but the heterogeneity remained significant $\left(\mathrm{I}^{2}=87 \%, p=\right.$ 0.0006) (Fig. 3).

\section{Secondary endpoint: Rate of response and remission}

One study (Stein et al. 2017 [29]) was not included in the secondary endpoint analysis, because it did not investigate difference between agomelatine and placebo in response or remission rate. The ORs of agomelatine over placebo for response and remission rates were 3.75 (95\% Cls, 2.76 to $5.09 ; p<0.00001)$ and $2.74(95 \% \mathrm{Cls}, 1.93$ 


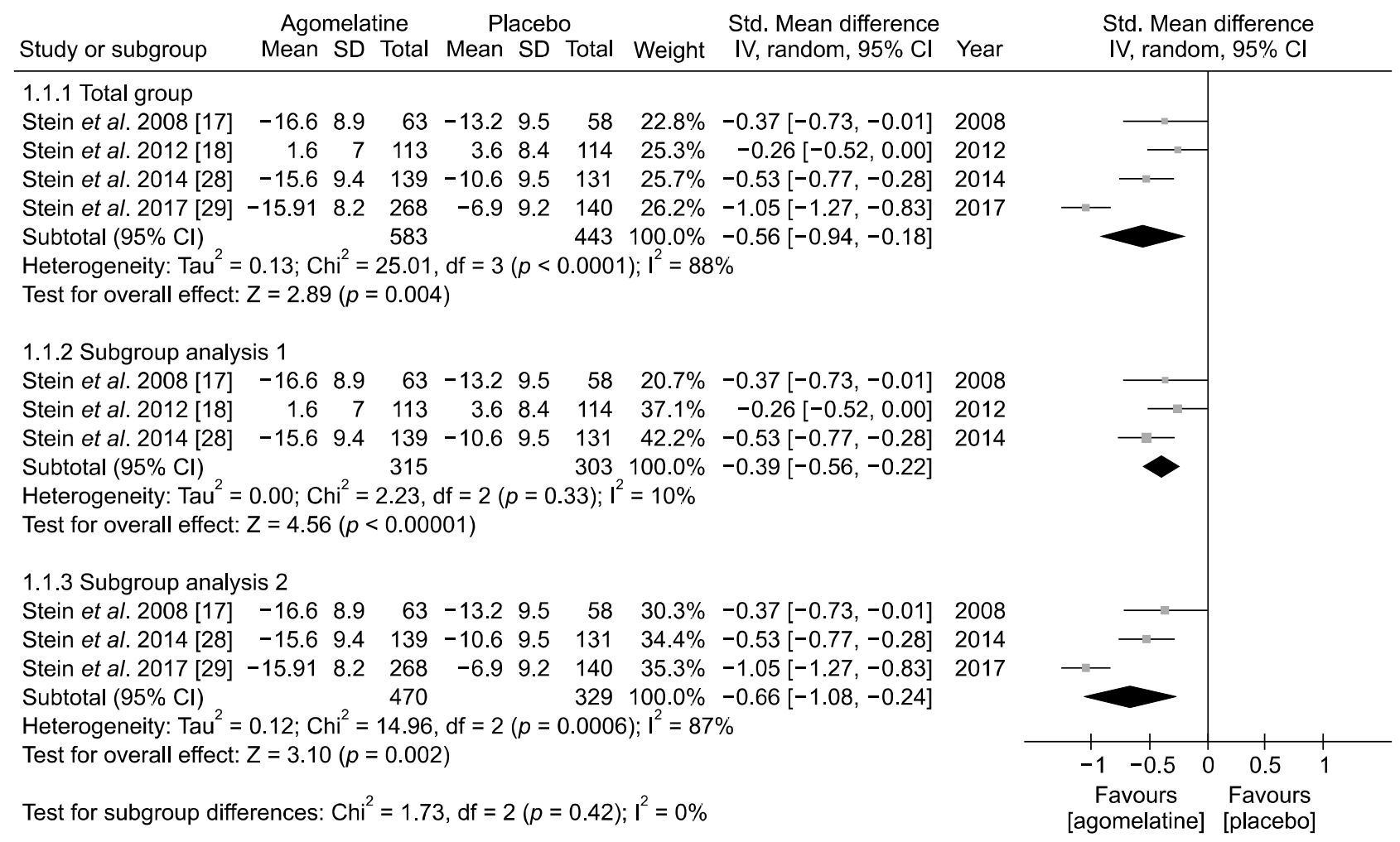

Fig. 3. Mean changes of Hamilton Anxiety Scale total score from baseline to end point between agomelatine and placebo treatment groubs. $\mathrm{SD}$, standard deviation; std, standardized; $95 \% \mathrm{Cl}, 95 \%$ confidence interval; IV, inverse variance.

A Response rate

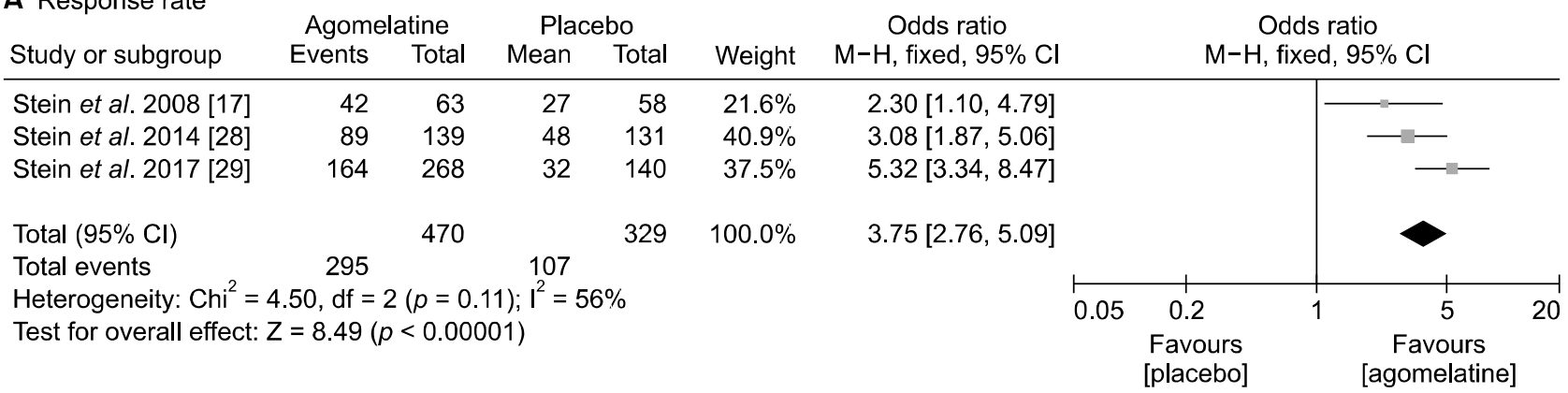

B Remission rate

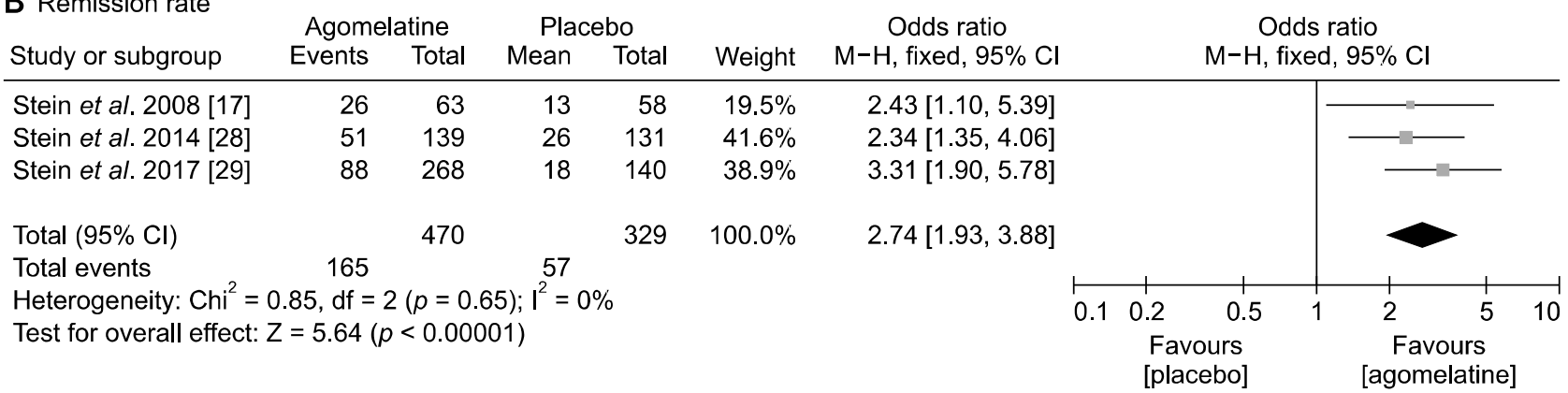

Fig. 4. Secondary efficacy measure: rate of (A) response and (B) remission between agomelatine and placebo. $\mathrm{M}-\mathrm{H}$; Mantel-Haenszel; $95 \% \mathrm{Cl}, 95 \%$ confidence interval. 
to $3.88 ; p<0.00001$ ), respectively (Fig. 4). For both, fixed model was utilized because no significant heterogeneity was noted.

\section{Safety and Tolerability}

Safety and tolerability of 4 RCTs for agomelatine are presented in Table 2. Total AEs were higher in agomelatine group than in placebo group, but they were statisti- cally not significant $(\mathrm{OR}, 1.25 ; 95 \%$ Cls, 0.96 to $1.62 ; p=$ 0.1 ). Dropout rate due to adverse event also did not significantly differ between two groups (Fig. 5). In terms of commonly observed side effects, agomelatine showed significantly higher incidence of LFT increment $(O R, 3.13$; 95\% Cls, 1.26 to $7.78 ; p=0.01)$ and nausea (OR, 3.27; 95\% Cls, 1.18 to 9.11; $p=0.02$ ) (Fig. 6). Lastly, agomelatine did not cause clinically significant somnolence,

Table 2. Safety and tolerability of 4 RCTs of agomelatine for the treatment of generalized anxiety disorder

\begin{tabular}{|c|c|c|c|c|c|c|c|c|c|c|c|c|}
\hline \multirow[b]{2}{*}{ Study } & \multirow[b]{2}{*}{ Drugs (mg/d) } & \multirow{2}{*}{$\begin{array}{l}\text { Patient } \\
\text { (n) }\end{array}$} & \multirow{2}{*}{$\begin{array}{c}\text { At least } 1 \\
\mathrm{AE}\end{array}$} & \multirow{2}{*}{$\begin{array}{c}\text { Increased } \\
\text { LFT }\end{array}$} & \multirow{2}{*}{ Nausea } & \multirow[b]{2}{*}{ Somnolence } & \multirow[b]{2}{*}{ Headache } & \multirow[b]{2}{*}{ NPT } & \multirow[b]{2}{*}{ Dizziness } & \multirow{2}{*}{$\begin{array}{l}\text { Dropout } \\
\text { due to } \\
\text { AE }\end{array}$} & \multicolumn{2}{|c|}{ SAE } \\
\hline & & & & & & & & & & & Patient & $\begin{array}{c}\text { Critical } \\
\text { illness }\end{array}$ \\
\hline \multirow{2}{*}{$\begin{array}{l}\text { Stein et al. } \\
2008 \text { [17] }\end{array}$} & PBO & 58 & $41(70.7)$ & 0 & $1(1.7)$ & - & $9(15.5)$ & $10(17.2)$ & $2(3.4)$ & 0 & 0 & 0 \\
\hline & $\operatorname{AGO}(25-50)$ & 63 & $37(58.7)$ & $2(3.2)$ & $3(4.8)$ & - & $9(14.3)$ & $7(11.1)$ & $5(7.9)$ & 1 & 0 & 0 \\
\hline \multirow{2}{*}{$\begin{array}{l}\text { Stein et al. } \\
2012 \text { [18] }\end{array}$} & PBO & 114 & $31(27.2)$ & $5(4.4)$ & $0(0)$ & $2(1.8)$ & $3(2.6)$ & $6(5.3)$ & $3(2.6)$ & $2(1.8)$ & 0 & 0 \\
\hline & AGO $(25-50)$ & 113 & $46(40.7)$ & 13 (11.5) & $5(4.4)$ & $3(2.7)$ & $12(10.6)$ & $6(5.3)$ & $4(3.5)$ & 0 & 0 & 0 \\
\hline \multirow{2}{*}{$\begin{array}{l}\text { Stein et al. } \\
2014[28]\end{array}$} & $\mathrm{PBO}$ & 131 & $58(44.3)$ & 0 & $1(0.8)$ & $1(0.8)$ & $14(10.7)$ & $7(5.3)$ & $4(3.1)$ & $4(3.1)$ & $4(3.1)$ & 0 \\
\hline & $\operatorname{AGO}(25-50)$ & 139 & $66(47.5)$ & $2(1.4)$ & $5(3.6)$ & $3(2.2)$ & $10(7.2)$ & $6(4.3)$ & $3(2.2)$ & $3(2.2)$ & $1(0.7)$ & 0 \\
\hline \multirow{2}{*}{$\begin{array}{l}\text { Stein et al. } \\
2017 \text { [29] }\end{array}$} & $\mathrm{PBO}$ & 140 & $36(25.7)$ & 0 & $2(1.4)$ & $1(0.7)$ & $9(6.4)$ & $1(0.7)$ & $3(2.1)$ & $2(1.4)$ & $2(1.4)$ & 0 \\
\hline & $\mathrm{AGO}(10-25)$ & 270 & $87(32.2)$ & $2(0.7)$ & $5(1.9)$ & $6(2.2)$ & $15(5.6)$ & $8(3.0)$ & $4(1.5)$ & $4(1.5)$ & $4(1.5)$ & 0 \\
\hline
\end{tabular}

Values are presented as number (\%).

RCT, randomized, double-blind, placebo-controlled trials; AE, adverse events; LFT, liver function test; NPT, nasopharyngitis; SAE, serious adverse events; PBO, placebo; AGO, agomelatine.

A Total adverse events

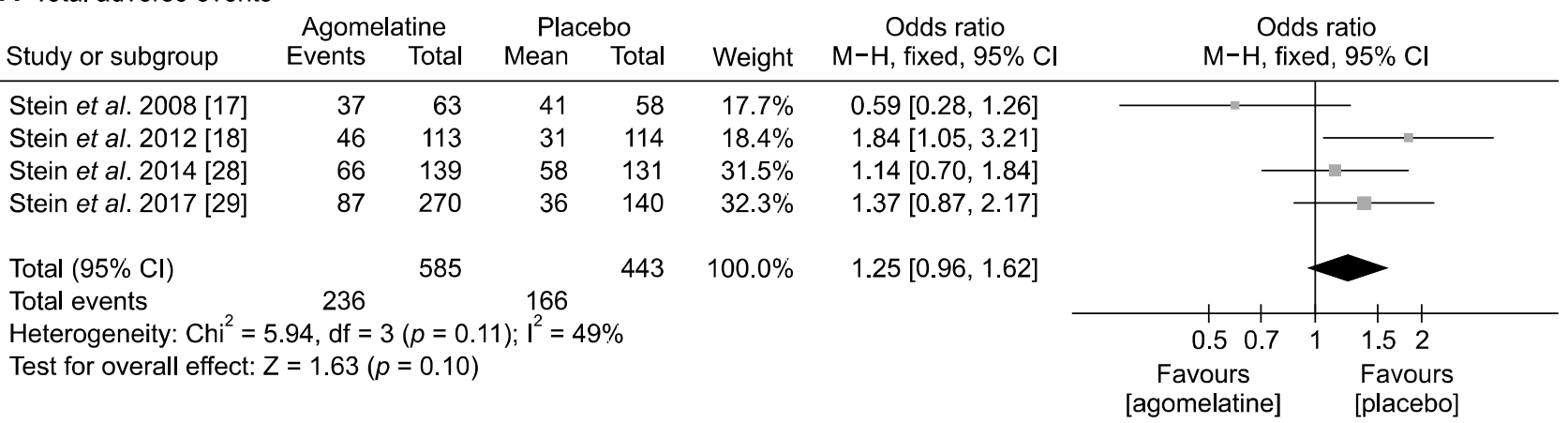

B Dropout due to adverse events

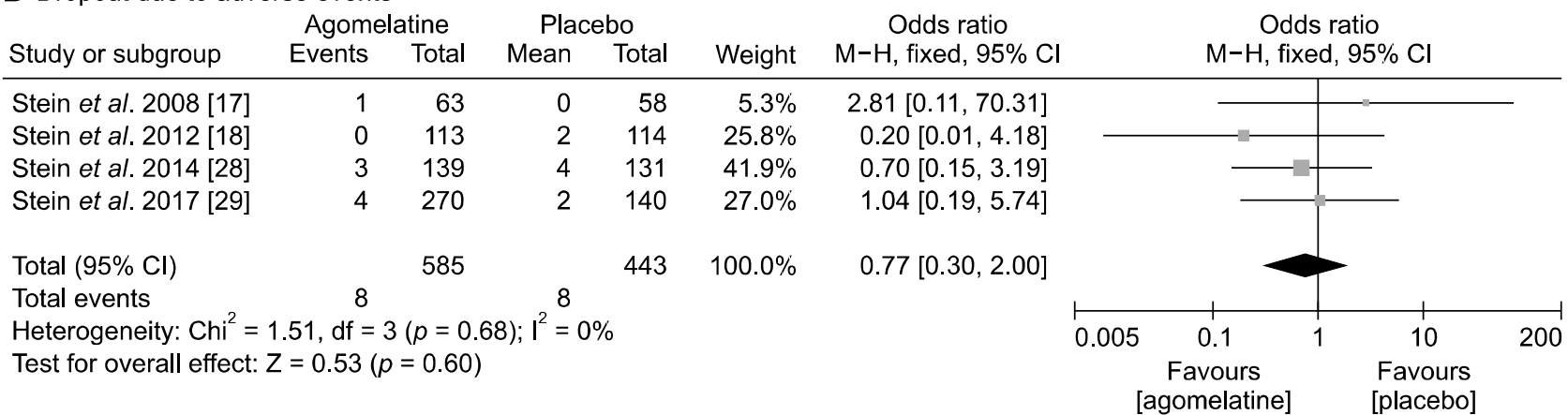

Fig. 5. Safety and tolerability: number of (A) total adverse events, (B) dropout due to adverse events. $\mathrm{M}-\mathrm{H}$; Mantel-Haenszel; $95 \% \mathrm{Cl}, 95 \%$ confidence interval. 


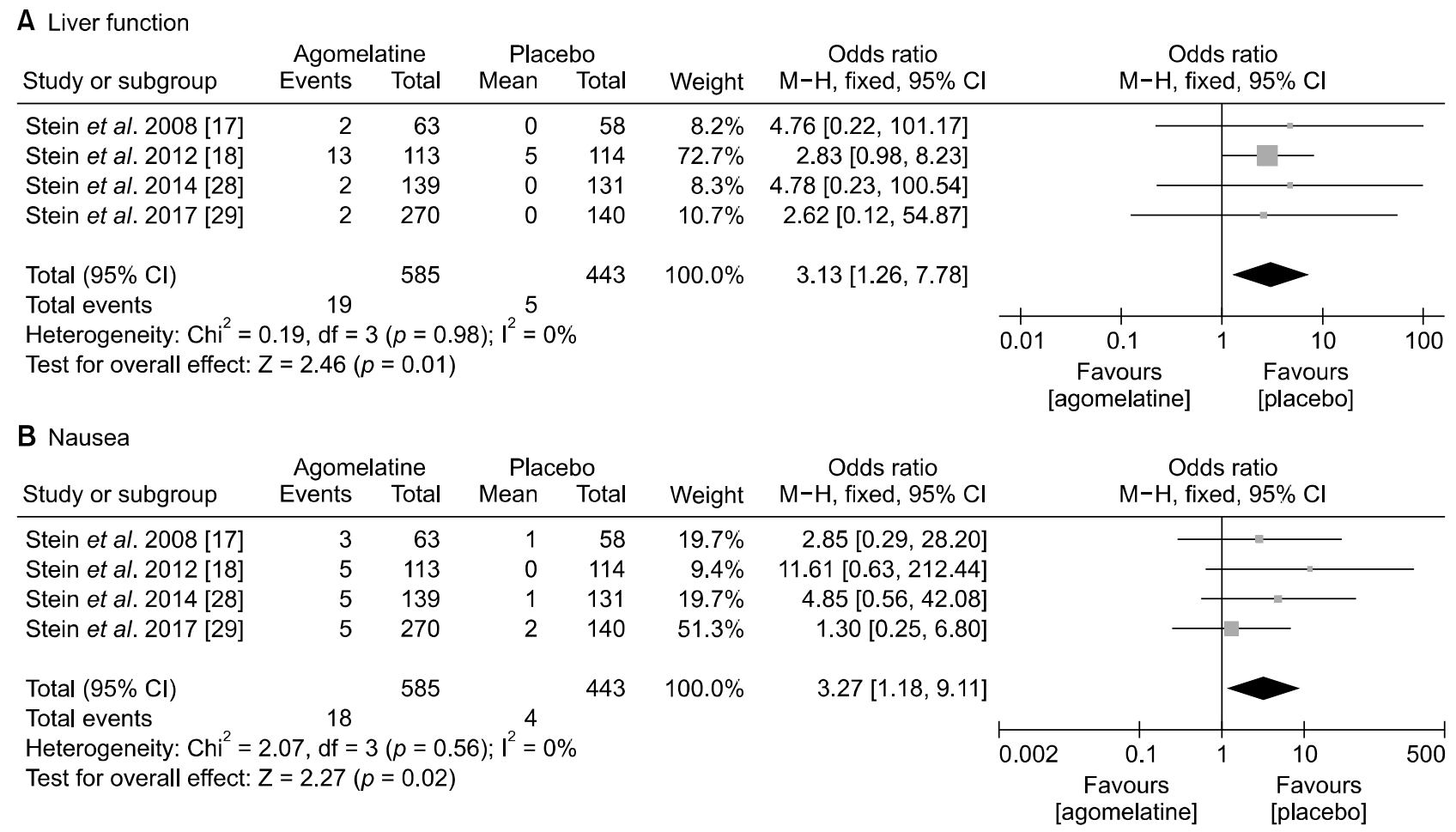

Fig. 6. Safety and tolerability: rate of (A) liver function test increment, (B) nausea. $\mathrm{M}-\mathrm{H}$; Mantel-Haenszel; $95 \% \mathrm{Cl}$, 95\% confidence interval.

headache, nasopharyngitis, and dizziness compared with placebo (Fig. 7).

\section{Number Needed to Treat and Number Needed to Harm}

Number needed to treat (NNT) and number needed to harm $(\mathrm{NNH})$ were also computed because they can quantify the effect sizes of clinically relevant benefits and harms of a certain drug [30]. By doing so, they have advantage of allowing clinicians to intuitively relate effect size difference back to real-world concerns of clinical practice [31]. For response rate, the risk difference between agomelatine and placebo was 0.32 (95\% Cls, 0.25 to 0.38 . Thus, NNT can be calculated as 3.13 . The risk difference between agomelatine and placebo for remission was 0.19 (95\% Cls, 0.13 to 0.25$)$ yielding NNT of 5.26. For safety and tolerability, NNH for nausea and LFT increment was analyzed because they were significantly higher than placebo. The risk difference for nausea and LFT increment was 0.02 (95\% Cls, 0.01 to 0.04 ) and 0.03 (95\% Cls, 0.01 to 0.05 ) yielding NNT of 50 and 33.3 .

\section{DISCUSSION}

Despite multiple pharmacological agents available, a large proportion of patients with GAD achieve neither adequate response nor complete remission [32]. The 5- $\mathrm{HT}_{2 \mathrm{C}}$ receptor antagonistic property of agomelatine's mechanism of action suggests its potential role in the treatment of GAD [22,33]. Thus, we aimed to investigate the efficacy and safety of agomelatine in the treatment of GAD by conducting a meta-analysis of RCTs.

Our results found 4 RCTs, and the meta-analysis demonstrated the statistically superior efficacy of agomelatine compared with placebo for the treatment of GAD. The differences in terms of mean changes in HAM-A total scores from baseline to endpoint (SMD, -0.56) was not small with median effect size according to Cohen's classification [34]. This effect size is comparable to the previous study showing SMD of pregabalin, hydroxyzine, venlafaxine, benzodiazepines and SSRIs vs. placebo in GAD as $0.50,0.45,0.42,0.38$, and 0.36 , respectively [35]. The ORs of agomelatine over placebo for response and remission rates were also notable with 3.75 and 2.74 respectively. In addition, the NNT for response and re- 


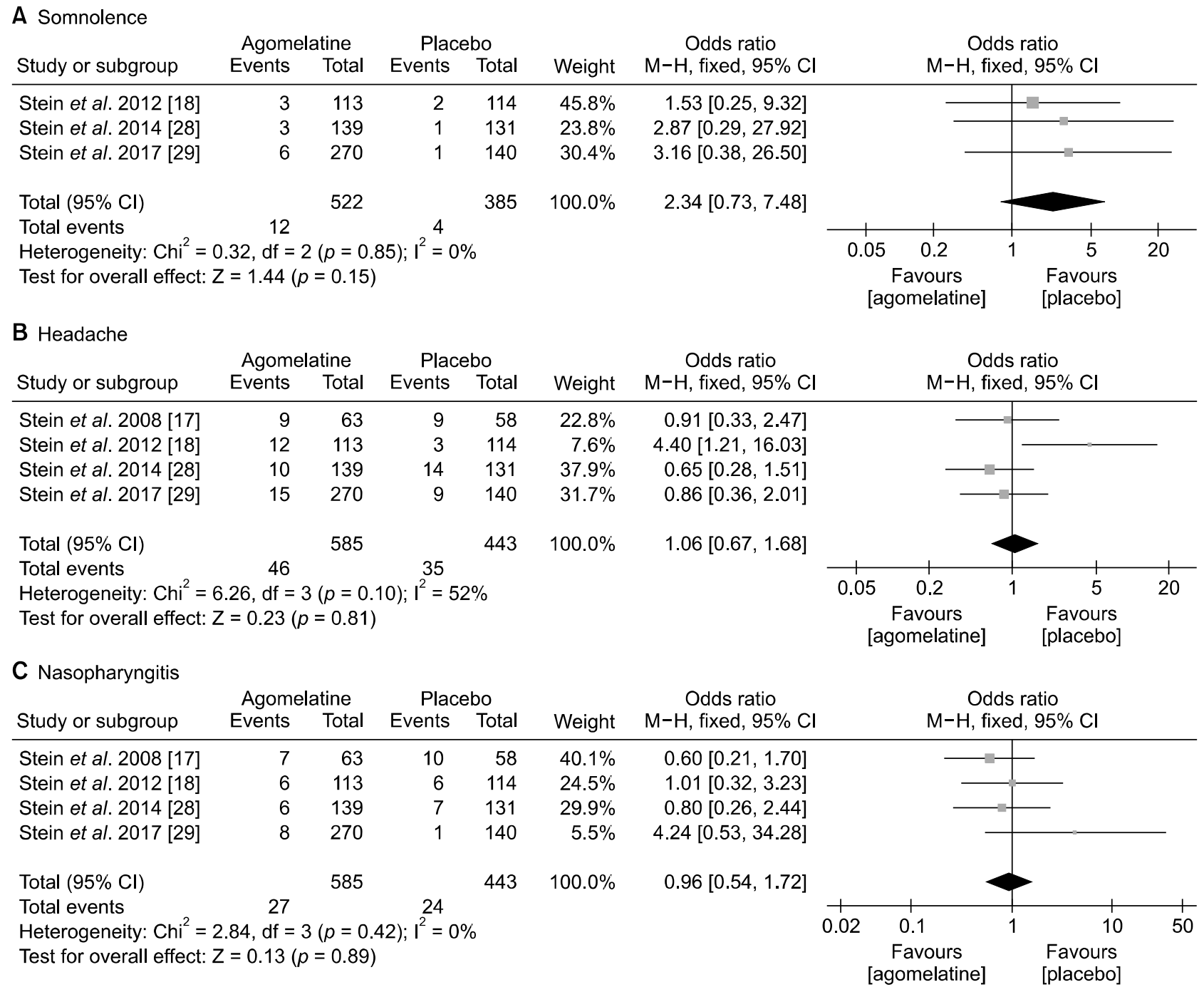

\section{Dizziness}

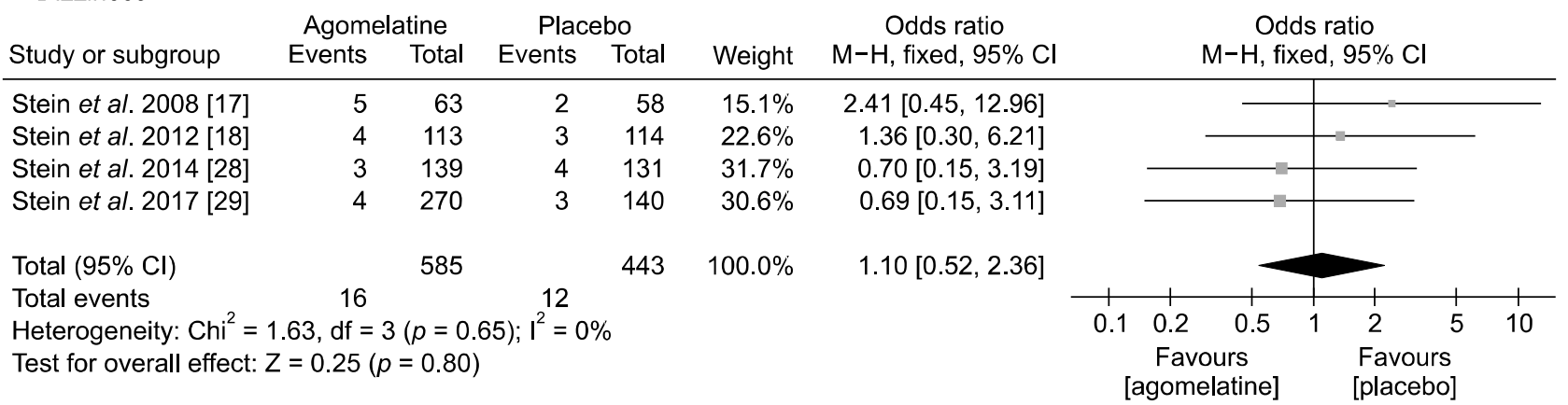

Fig. 7. Safety and tolerability: rate of (A) somnolence, (B) headache, (C) nasopharyngitis, (D) dizziness.

$\mathrm{M}-\mathrm{H}$; Mantel-Haenszel; $95 \% \mathrm{Cl}, 95 \%$ confidence interval.

mission were 3.13 and 5.26 respectively, which corresponds to "somewhat treatable." [31]. However, more RCTs are needed to confirm efficacy and establish more correct effect size of agomelatine in GAD.
In line with previous meta-analysis of agomelatine in the treatment of MDD, agomelatine was generally well tolerated and safe $[36,37]$. Above all, most of side effects observed in both groups were mild or moderate in 
severity. No SAEs led to clinically critical conditions. A trend of higher total AEs was found in agomelatine group than in placebo group, but they were statistically not significant group (OR, 1.25, $p=0.1$ ). In addition, dropout rate due to adverse event and rate of somnolence, headache, nasopharyngitis, and dizziness did not differ between the two group. However, the rate of nausea was significantly higher in agomelatine than in placebo group (OR, 3.27; $p=0.02$ ). The risk of agomelatine causing liver injury has been well documented [38]. Likewise, our meta-analysis also showed that agomelatine caused significantly higher incidence of LFT increment (OR, 3.13; $p=$ 0.01 ) than placebo. $\mathrm{NNH}$ for nausea and LFT increment were 50 and 33.3 respectively. Thus, monitoring of LFT before initiating and during treatment with agomelatine is necessary.

The study contains several limitations. First, our results were based on a total of 4 RCTs with a pooled sample size (agomelatine and placebo) of 1,024 patients only. Therefore, we combined all doses of agomelatine and were unable to undertake meta-regression to understand its dose related efficacy and safety. We were also unable to conduct meta-regression and investigate possible linear relationship between outcome measure and other covariates. Second, all studies were conducted outside North America, so more studies are needed in diverse regions worldwide to increase generalizability. Third, we were not able to find unpublished trials, so there is a possibility of publication bias. Fourth, all 4 studies were financially sponsored by pharmaceutical company owning Valdoxan, a brand name for agomelatine, Servier. Moreover, all 4 trials were led by the same author (Stein) and employees of Servier were also involved as co-authors. Thus, industry bias could have influenced to yield a positive result $[39,40]$.

Despite these limitations, our study has major strengths. To the best of our knowledge, this is the first meta-analysis to evaluate the benefits and risk of agomelatine for treatment of GAD. All RCTs included were multi-centered, multi-national, and carefully designed. The demographics of the studies including age range, mean age, sex ratio, and inclusion criteria were comparable reducing clinical heterogeneity. In addition, despite significant heterogeneity noted, magnitude of the difference in reduction of HAM-A, response rate, and remission rate between agomelatine and placebo was relatively large. Thus, the dif- ference was observed regardless of using fixed or random effect model.

In conclusion, the present meta-analysis suggested that agomelatine may be another treatment option for patients with GAD. However, the results should be interpreted and translated into clinical practice cautiously because only 4 RCTs are conducted worldwide. Thus, our results urge that more adequately powered, well-designed, placebo-controlled clinical trials are clearly needed to confirm agomelatine's clinical utility in treatment of GAD.

\section{- Acknowledgments}

This work was supported by the National Research Foundation of Korea (NRF) grant funded by the Korea government (MSIT) (No. 2019R1A2C2009100).

\section{- Conflicts of Interest}

No potential conflict of interest relevant to this article was reported.

\section{author Contributions}

Sheng-Min Wang and Won-Myong Bahk designed the study. Nak-Young Kim and Hae-Ran Na acquired data, Hyun Kook Lim and Young Sup Woo analysed the data. Finally, Sheng-Min Wang wrote the article, which all authors reviewed and approved for publication.

\section{ORCID}

Sheng-Min Wang https://orcid.org/0000-0003-2521-1413

Young Sup Woo https://orcid.org/0000-0002-0961-838X

Nak-Young Kim https://orcid.org/0000-0003-0116-6283

Hae-Ran Na https://orcid.org/0000-0002-7960-8603

Hyun Kook Lim https://orcid.org/0000-0001-8742-3409

Won-Myong Bahk https://orcid.org/0000-0002-0156-2510

\section{REFERENCES}

1. Wittchen HU, Jacobi F. Size and burden of mental disorders in Europe: a critical review and appraisal of 27 studies. Eur Neuropsychopharmacol 2005;15:357-376.

2. Findıklı E, Camkurt MA, İzci F, Karaaslan MF, Findıklı HA, Sümer $\mathrm{P}$, et al. The diagnostic value of malondialdehyde, superoxide dismutase and catalase activity in drug naïve, first episode, non-smoker generalized anxiety disorder patients. Clin Psychopharmacol Neurosci 2018;16:88-94.

3. Hoffman DL, Dukes EM, Wittchen HU. Human and economic burden of generalized anxiety disorder. Depress Anxiety 2008;25:72-90. 
4. Wittchen HU, Carter RM, Pfister H, Montgomery SA, Kessler RC. Disabilities and quality of life in pure and comorbid generalized anxiety disorder and major depression in a national survey. Int Clin Psychopharmacol 2000;15:319-328.

5. Xin LM, Chen L, Ji ZP, Zhang SY, Wang J, Liu YH, et al. Risk factors for anxiety in major depressive disorder patients. Clin Psychopharmacol Neurosci 2015;13:263-268.

6. Strawn JR, Geracioti L, Rajdev N, Clemenza K, Levine A. Pharmacotherapy for generalized anxiety disorder in adult and pediatric patients: an evidence-based treatment review. Expert Opin Pharmacother 2018;19:1057-1070.

7. Serretti A. The present and future of precision medicine in psychiatry: focus on clinical psychopharmacology of antidepressants. Clin Psychopharmacol Neurosci 2018;16:1-6.

8. Seo JS, Bahk WM, Wang HR, Woo YS, Park YM, Jeong JH, et al. Korean Medication Algorithm for Depressive Disorders 2017: third revision. Clin Psychopharmacol Neurosci 2018; 16:67-87.

9. Buoli M, Caldiroli A, Caletti E, Paoli RA, Altamura AC. New approaches to the pharmacological management of generalized anxiety disorder. Expert Opin Pharmacother 2013;14: 175-184.

10. Wittchen HU. Generalized anxiety disorder: prevalence, burden, and cost to society. Depress Anxiety 2002;16:162-171.

11. Norman TR, Olver JS. Agomelatine for depression: expanding the horizons? Expert Opin Pharmacother 2019;20:647-656.

12. Papp M, Litwa E, Gruca P, Mocaër E. Anxiolytic-like activity of agomelatine and melatonin in three animal models of anxiety. Behav Pharmacol 2006;17:9-18.

13. Tuma J, Strubbe JH, Mocaër E, Koolhaas JM. Anxiolytic-like action of the antidepressant agomelatine (S 20098) after a social defeat requires the integrity of the SCN. Eur Neuropsychopharmacol 2005; 15:545-555.

14. Conboy L, Tanrikut C, Zoladz PR, Campbell AM, Park CR, Gabriel C, et al. The antidepressant agomelatine blocks the adverse effects of stress on memory and enables spatial learning to rapidly increase neural cell adhesion molecule (NCAM) expression in the hippocampus of rats. Int I Neuropsychopharmacol 2009;12:329-341.

15. Millan MJ, Brocco M, Gobert A, Dekeyne A. Anxiolytic properties of agomelatine, an antidepressant with melatoninergic and serotonergic properties: role of 5-HT2C receptor blockade. Psychopharmacology (Berl) 2005;177:448-458.

16. Kasper S, Hajak G, Wulff K, Hoogendijk WJ, Montejo AL, Smeraldi $\mathrm{E}$, et al. Efficacy of the novel antidepressant agomelatine on the circadian rest-activity cycle and depressive and anxiety symptoms in patients with major depressive disorder: a randomized, double-blind comparison with sertraline. J Clin Psychiatry 2010;71:109-120.

17. Stein DJ, Ahokas AA, de Bodinat C. Efficacy of agomelatine in generalized anxiety disorder: a randomized, double-blind, placebo-controlled study. J Clin Psychopharmacol 2008;28: 561-566.
18. Stein DJ, Ahokas A, Albarran C, Olivier V, Allgulander C. Agomelatine prevents relapse in generalized anxiety disorder: a 6-month randomized, double-blind, placebo-controlled discontinuation study. J Clin Psychiatry 2012;73: 1002-1008.

19. Igwe SC, Brigo F. Does melatonin and melatonin agonists improve the metabolic side effects of atypical antipsychotics?: a systematic review and meta-analysis of randomized controlled trials. Clin Psychopharmacol Neurosci 2018;16:235245.

20. Wang SM, Han C, Lee SJ, Jun TY, Patkar AA, Masand PS, et al. Modafinil for the treatment of attention-deficit/hyperactivity disorder: a meta-analysis. J Psychiatr Res 2017;84:292-300.

21. Cheung MW, Vijayakumar R. A guide to conducting a meta-analysis. Neuropsychol Rev 2016;26:121-128.

22. Demyttenaere K. Agomelatine in treating generalized anxiety disorder. Expert Opin Investig Drugs 2014;23:857-864.

23. Higgins JP, Altman DG, Gøtzsche PC, Jüni P, Moher D, Oxman $\mathrm{AD}$, et al. The Cochrane Collaboration's tool for assessing risk of bias in randomised trials. BMJ 2011;343: d5928.

24. Nakagawa S, Noble DW, Senior AM, Lagisz M. Meta-evaluation of meta-analysis: ten appraisal questions for biologists. BMC Biol 2017;15:18.

25. Melsen WG, Bootsma MC, Rovers MM, Bonten MJ. The effects of clinical and statistical heterogeneity on the predictive values of results from meta-analyses. Clin Microbiol Infect 2014;20:123-129.

26. von Hippel PT. The heterogeneity statistic $P^{2}$ can be biased in small meta-analyses. BMC Med Res Methodol 2015;15:35.

27. Brockwell SE, Gordon IR. A comparison of statistical methods for meta-analysis. Stat Med 2001;20:825-840.

28. Stein DJ, Ahokas A, Márquez MS, Höschl C, Oh KS, Jarema M, et al. Agomelatine in generalized anxiety disorder: an active comparator and placebo-controlled study. J Clin Psychiatry 2014;75:362-368.

29. Stein DJ, Ahokas A, Jarema M, Avedisova AS, Vavrusova L, Chaban $\mathrm{O}$, et al. Efficacy and safety of agomelatine (10 or 25 $\mathrm{mg} /$ day) in non-depressed out-patients with generalized anxiety disorder: A 12-week, double-blind, placebo-controlled study. Eur Neuropsychopharmacol 2017;27:526-537.

30. Altman DG, Deeks JJ. Meta-analysis, Simpson's paradox, and the number needed to treat. BMC Med Res Methodol 2002; 2:3.

31. Citrome $\mathrm{L}$, Ketter TA. When does a difference make a difference? Interpretation of number needed to treat, number needed to harm, and likelihood to be helped or harmed. Int J Clin Pract 2013;67:407-411.

32. Reinhold JA, Rickels K. Pharmacological treatment for generalized anxiety disorder in adults: an update. Expert Opin Pharmacother 2015;16:1669-1681.

33. Wood MD. Therapeutic potential of 5-HT2C receptor antagonists in the treatment of anxiety disorders. Curr Drug Targets 
CNS Neurol Disord 2003;2:383-387.

34. Faraone SV. Interpreting estimates of treatment effects: implications for managed care. P\&T 2008;33:700-711.

35. Hidalgo RB, Tupler LA, Davidson JR. An effect-size analysis of pharmacologic treatments for generalized anxiety disorder. J Psychopharmacol 2007;21:864-872.

36. Taylor D, Sparshatt A, Varma S, Olofinjana O. Antidepressant efficacy of agomelatine: meta-analysis of published and unpublished studies. BMJ 2014;348:g1888.

37. Huang KL, Lu WC, Wang YY, Hu GC, Lu CH, Lee WY, et al. Comparison of agomelatine and selective serotonin reuptake inhibitors/serotonin-norepinephrine reuptake inhibitors in major depressive disorder: a meta-analysis of head-to-head randomized clinical trials. Aust N Z J Psychiatry 2014;48: 663-671.

38. Freiesleben SD, Furczyk K. A systematic review of agomelatine-induced liver injury. J Mol Psychiatry 2015;3:4.

39. Lundh A, Lexchin J, Mintzes B, Schroll JB, Bero L. Industry sponsorship and research outcome: systematic review with meta-analysis. Intensive Care Med 2018;44:1603-1612.

40. Bero L. Industry sponsorship and research outcome: a Cochrane review. JAMA Intern Med 2013;173:580-581. 